\title{
PERIKANAN DEMERSAL DI SEKITAR KEPULAUAN TOGEAN, TELUK TOMINI*)
}

\author{
Awwaluddin"), Rusmadji Rustam²), dan Suwarso') \\ 1) Peneliti pada Balai Riset Perikanan Laut-Muara Baru, Jakarta \\ 2) Peneliti pada Balai Pengkajian Teknologi Pertanian, Semarang \\ Teregristrasi I tanggal: 12 April 2006; Disetujui terbit tanggal: 12 September 2006
}

\begin{abstract}
ABSTRAK
Penelitian perikanan demersal dan ikan-ikan karang di daerah sekitar Kepulauan Togean, Teluk Tomini telah dilakukan pada tahun 2004. Data yang dikumpulkan dari daerah pengambilan contoh Kecamatan Pagimana, Kabupaten Banggai berupa data-data primer hasil pengambilan contoh pada bulan Agustus dan Desember 2004 yang meliputi data alat tangkap pancing dasar, daerah penangkapan ikan, komposisi jenis, laju tangkap ikan, dan ukuran panjang dan bobot ikan hasil tangkapan dominan. Data sekunder untuk mendukung hasil penelitian diperoleh dari enumerator dan PPI Pagimana, Kecamatan Pagimana, Kabupaten Banggai, Sulawesi Tengah. Berdasarkan pada hasil penelitian dapat diketahui bahwa alat tangkap utama dan dominan untuk menangkap ikan demersal di perairan Kepulauan Togean adalah pancing rawai dasar. Perahu yang digunakan adalah perahu jukung yang dilengkapi katir dan berdimensi $(\mathrm{LxBXD})=(700 \times 60 \times 100) \mathrm{cm}$ berkekuatan $5,5 \mathrm{pk}$. Daerah penangkapan nelayan pancing hampir di seluruh perairan Teluk Tomini, khusus daerah-daerah yang berkarang seperti di Kepulauan Togean (sekitar Pulau Poat, Pulau Bangoh, dan Tanjung Keramat), Dondola sampai dengan di utara Bualemo. Penangkapan ikan ke sekitar Kepulauan Togean (Pulau Poat, Pulau Bangoh, dan Tanjung Keramat) dilakukan sepanjang tahun, hal ini karena daerah penangkapan tersebut relatif dekat dan mudah dicapai. Konsentrasi pendaratan ikan demersal hasil pancingan di wilayah Kabupaten Banggai adalah di PPI Pagimana, Banggai Kepulauan, Bualemo, dan Toili. Hasil tangkapan pancing dasar didominasi oleh jenis kerapu atau grouper (Serranidae), kakap (Lutjanidae), daging putih atau lencam (Lethrinidae) dan suntung batu (Sephia sp.), serta gurita (Octopus sp.). Pada bulan Mei sampai dengan Desember 2004 laju tangkap harian berkisar antara 10,8 sampai dengan 65,4 kg per kapal per hari. Jenis ikan daging putih atau lencam (Lethrinidae) pada umumnya mendominasi hasil tangkapan setiap bulan dengan persentase rata-rata tertangkap 35,04\%. Jenis-jenis kerapu atau Serranidae (Plectropomus sp., Ephinephelus sp., Variola sp.) dan jenis-jenis kakap atau Lutjanidae (Lutjanus sp., Aprion sp., dan Pristipomoides sp.) yang merupakan sasaran tangkapan utama memiliki persentase rata-rata tertangkap cukup tinggi yaitu masing-masing 18,96 dan 18,82\%. Jenis tangkapan lain yang juga mendominasi adalah gurita (Octopus sp.) yang rata-rata mencapai 13,45\%, suntung batu (Sepia sp.) rata-rata 3,34\%. Berdasarkan pada hasil pengukuran panjang beberapa jenis ikan dominan, ukuran panjang jenis ikan ekor bulan (Variola albimarginata) yang tertangkap berkisar antara 24 sampai dengan $34 \mathrm{~cm}$. Jenis ikan sunu super (Plectropomus leopardus) yang tertangkap mempunyai ukuran panjang yang berkisar antara 28 sampai dengan $49 \mathrm{~cm}$. Kerapu coklat (Ephinephelus areolatus) yang tertangkap mempunyai ukuran 40 sampai dengan $82 \mathrm{~cm}$. Ukuran ikan kakap merah (Lutjanus malabaricus) berkisar antara 40,5 sampai dengan $72,5 \mathrm{~cm}$. Sunu macan (Plectropomus areolatus) berukuran antara 39 sampai dengan $64 \mathrm{~cm}$. Kerapu muso atau gomes (Ephinephelus fuscoguttatus) pada umumnya memiliki ukuran yang lebih besar bila dibandingkan dengan jenis ikan lain dengan ukuran panjang antara 64 sampai dengan $89 \mathrm{~cm}$. Pemantauan aktivitas penangkapan nelayan di wilayah ini harus dilakukan untuk menghindari terjadi penangkapan yang illegal maupun penangkapan yang tidak memperhatikan kelestarian.
\end{abstract}

KATA KUNCI: ikan demersal, perikanan, bottom long line, Kepulauan Togean, Teluk Tomini

\section{PENDAHULUAN}

Perairan Teluk Tomini yang secara administratif masuk ke dalam wilayah beberapa propinsi mulai dari Sulawesi Utara, Gorontalo, dan Sulawesi Timur memiliki potensi sumber daya perikanan yang sangat beranekaragam. Potensi perikanan di Teluk Tomini antara lain perikanan pelagis kecil (layang dan kembung), pelagis besar (tuna dan cakalang), dan ikan demersal karang (kerapu, kakap, dan lencam).
Menurut Anonim (2001) potensi perikanan di Teluk Tomini sekitar 585,5 ton per tahun dan $83 \%$ (486 ton) antara lain sumber daya ikan pelagis. Penelitian mengenai ikan pelagis di perairan Teluk Tomini secara umum maupun di Kepulauan Togean telah banyak dilakukan antara lain mengenai potensi sumber daya ikan di perairan Laut Maluku dan Teluk Tomini (Badruddin et al., 1992); studi pengaruh rumpon terhadap perilaku ruaya ikan cakalang, Katsuwonus pelamis, dan madidihang, Thunnus 
albacares dengan metode tagging kawasan Indonesia Timur (Gafa \& Subani, 1993) dan lain-lain, sedangkan penelitian mengenai sumber daya ikan demersal karang di perairan Teluk Tomini belum terdata.

Kecamatan Pagimana di Kabupaten Banggai, Sulawesi Tengah merupakan salah satu daerah penting bagi perikanan di Sulawesi. Nelayan Kecamatan Pagimana banyak menangkap ikan dari perairan Teluk Tomini, khusus di Kepulauan Togean yang kemudian didistribusikan ke daerah-daerah di propinsi lain di Sulawesi. Selain itu, ada beberapa perusahaan pengekspor dalam bentuk ikan segar maupun ikan olahan seperti fillet ikan memberikan kontribusi yang positif bagi pendapatan nelayan Pagimana.

Kepulauan Togean secara geografis terletak pada posisi 0॰8'21"-045'12" LS dan 121 $31^{\circ} 21^{\prime \prime}$ $122^{\circ} 23^{\prime} 36^{\prime \prime}$ BT dengan luas 763,33 km². Hasil tangkapan utama di Kepulauan Togean, Kecamatan Pagimana merupakan sumber daya ikan demersal. Peningkatan harga ikan demersal di daerah ini terus membaik sejak tahun 2003 setelah berdiri beberapa perusahaan pengekspor yang dapat memasarkan hasil tangkapan nelayan dalam bentuk frozen, fillet, maupun dalam bentuk segar. Semakin tinggi harga ikan demersal ini sangat memungkinkan terjadi gejala lebih tangkap (over fishing) dan penangkapan ikan secara ilegal seperti pembiusan dan pengeboman ikan.

Ikan demersal yang berupa populasi ikan karang di perairan Teluk Tomini merupakan asset yang potensial bagi berbagai pihak. Pada umumnya penangkapan dilakukan oleh para nelayan pancing di sekitar perairan tersebut, namun potensi biomassa dan nilai produksi sulit diprediksi akibat keterbatasan pendataan. Data mengenai dugaan potensi, stok sumber daya, dan data laju tangkap ikan demersal, sampai dengan saat ini sangat minim sehingga perlu dilakukan kajian yang mendalam mengenai sumber daya ikan demersal di daerah ini. Hal ini, yang mendasari dilakukan observasi di wilayah perairan Teluk Tomini yang dilakukan pada tahun 2004, yang diharapkan dapat memberikan kontribusi yang cukup baik sebagai informasi untuk menetapkan kebijakankebijakan dalam pengembangan perikanan demersal di perairan Teluk Tomini.

Tujuan penelitian ini adalah untuk memperoleh data dan informasi mengenai daerah penangkapan ikan (fishing ground), alat dan sarana penangkapan, laju tangkap harian (kg per hari per kapal), komposisi jenis hasil tangkapan dan data biologi hasil tangkapan yang meliputi ukuran (panjang bobot) dari jenis ikanikan dominan.

Perolehan data dibedakan atas 2 jenis data, yaitu data primer dan data sekunder. Pengumpulan data primer yang dilakukan pada bulan Agustus dan Desember 2004, meliputi:

1. Alat tangkap yang digunakan nelayan demersal karang di Kecamatan Pagimana, Kabupaten Banggai.

2. Daerah penangkapan (fishing ground) menggunakan GPS.

3. Identifikasi jenis-jenis hasil tangkapan yang dominan (meliputi jenis kerapu dan kakap) dengan melakukan pengambilan contoh di nelayan, padola (pengumpul) dan di PPI Pagimana. Identifikasi diilakukan dengan menggunakan referensi trawled fishes (GloefertTarp \& Kailola, 1985) dan groupers of the world (Heemstra \& Randal, 1993).

4. Pengambilan contoh biologi (pengukuran panjang bobot dan pengambilan contoh isi perut serta gonad) dilakukan di PPI Pagimana dan dari salah satu perusahaan ekspor fillet ikan-ikan demersal di Luwuk, Kabupaten Banggai.

Perolehan data sekunder dilakukan dengan mengumpulkan data dari enumerator dan pengumpul ikan demersal di Kabupaten Banggai.

\section{Jenis Alat Tangkap}

Alat tangkap yang digunakan oleh nelayan di Kecamatan Pagimana, pada umumnya adalah pancing dasar. Ada 2 jenis pancing, yaitu pancing dasar biasa (handline) dan pancing rawai dasar yang telah di modifikasi. Modifikasi pancing rawai dasar tersebut meliputi konstruksi dan cara operasional, seperti ditunjukkan dalam Gambar 1.

\section{Operasional Pancing}

Pancing rawai dasar ini terdiri atas 2 buah pemberat (masing-masing $3 \mathrm{~kg}$ ) pada setiap ujung tali utama. Pemberat pertama diturunkan terlebih dahulu, kemudian tali utama yang mempunyai panjang $30 \mathrm{~m}$ (3 sampai dengan 5 mata pancing; jarak antar mata pancing 7,5 m) kemudian pemberat ke-2, dan berikut adalah tali tambang yang menghubungkan pelampung dengan pemberat dan tali utama yang mempunyai panjang disesuaikan dengan kedalaman (100 sampai dengan $200 \mathrm{~m}$ ). Agar pancing tidak terbawa arus, maka pelampung akan diikatkan ke batu karang dengan menggunakan seutas tali tambang. Pancing dipasang pada sore hari, dengan alasan bahwa ikan karang mencari makan pada sore hari sampai dengan menjelang pagi. Pancing yang telah dipasang akan ditinggalkan selama 1 malam dan dijaga pada jarak tertentu. Sebelum pancing diangkat, pancing akan ditarik dengan menggunakan kapal berkecepatan 


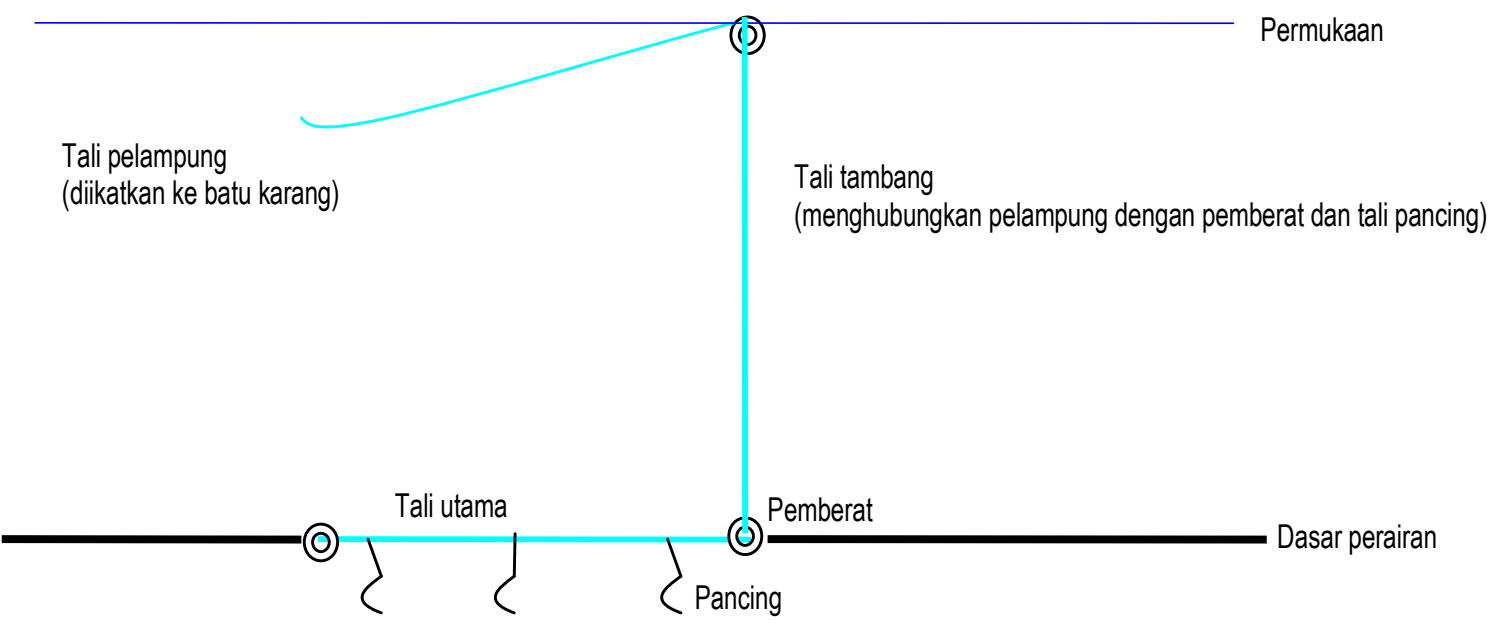

Keterangan: Mata pancing No.1; tali utama berupa tali nylon No.400

Gambar 1. Konstruksi dan setting pancing di perairan karang.

rendah. Kapal yang digunakan kapal jukung dengan kekuatan mesin ktinting 5,5 pk (Gambar 2).

\section{Daerah Penangkapan}

Penangkapan ikan dilakukan sepanjang tahun, baik musim barat, peralihan, maupun musim timur. Daerah penangkapan nelayan pancing hampir di seluruh perairan Teluk Tomini, khusus daerah-daerah yang berkarang seperti di Kepulauan Togean, Dondola, sampai dengan di utara Bualemo.

1. Pada musim barat, nelayan melakukan penangkapan ke perairan Pulau Buaya-Bualemo, selain itu daerah penangkapan juga ke sekitar Pulau Poat, Pulau Bangoh, sampai dengan Tanjung Keramat.
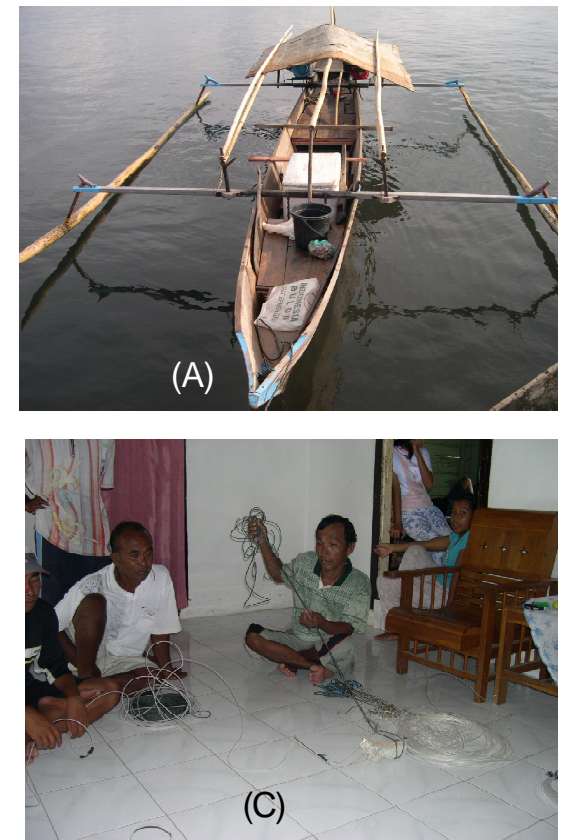
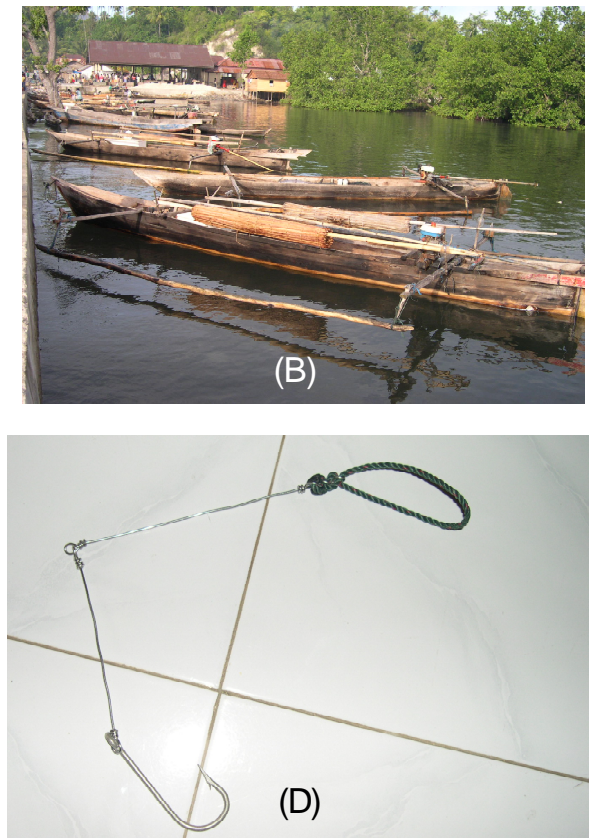

Gambar 2. Perahu (A); alat tangkap pancing (B) yang digunakan nelayan pancing di Pagimana (Kabupaten Banggai); (C) perahu kayu berkatir, dimensi (LxBxD) 700x60x100) cm; dan (D) mata pancing No.1, benang nylon No.400 sebagai tali utama, pemberat menggunakan 2 buah batu @ kg, setiap pancing terdiri atas 3 sampai dengan 5 mata pancing dengan jarak antara 7,5 m, setiap kapal penangkap membawa 3 sampai dengan 5 alat pancing. 
2. Pada musim timur, nelayan pada umumnya menangkap di sekitar Kepulauan Togean, terutama di perairan Pulau Poat dan perairan Tanjung Keramat di Pulau Waleabahi yang merupakan daerah wisata dan konservasi terumbu karang.

Penangkapan ikan ke sekitar Kepulauan Togean (Pulau Poat, Pulau Bangoh, dan Tanjung Keramat) dilakukan sepanjang tahun, hal ini karena daerah penangkapan tersebut relatif dekat dan mudah dicapai.
Konsentrasi pendaratan ikan demersal hasil pancingan di wilayah Kabupaten Banggai adalah di PPI Pagimana, Banggai Kepulauan, Bualemo, dan Toili.

Pada musim timur, waktu melaut antara 3 sampai dengan 7 hari per trip. Konsentrasi pendaratan ikan demersal hasil pancingan adalah di PPI Pagimana, Kepulauan Banggai, Bualemo, dan Toili. Hasil monitoring mengikuti nelayan pancing pada musim timur disajikan pada gambar 3 .

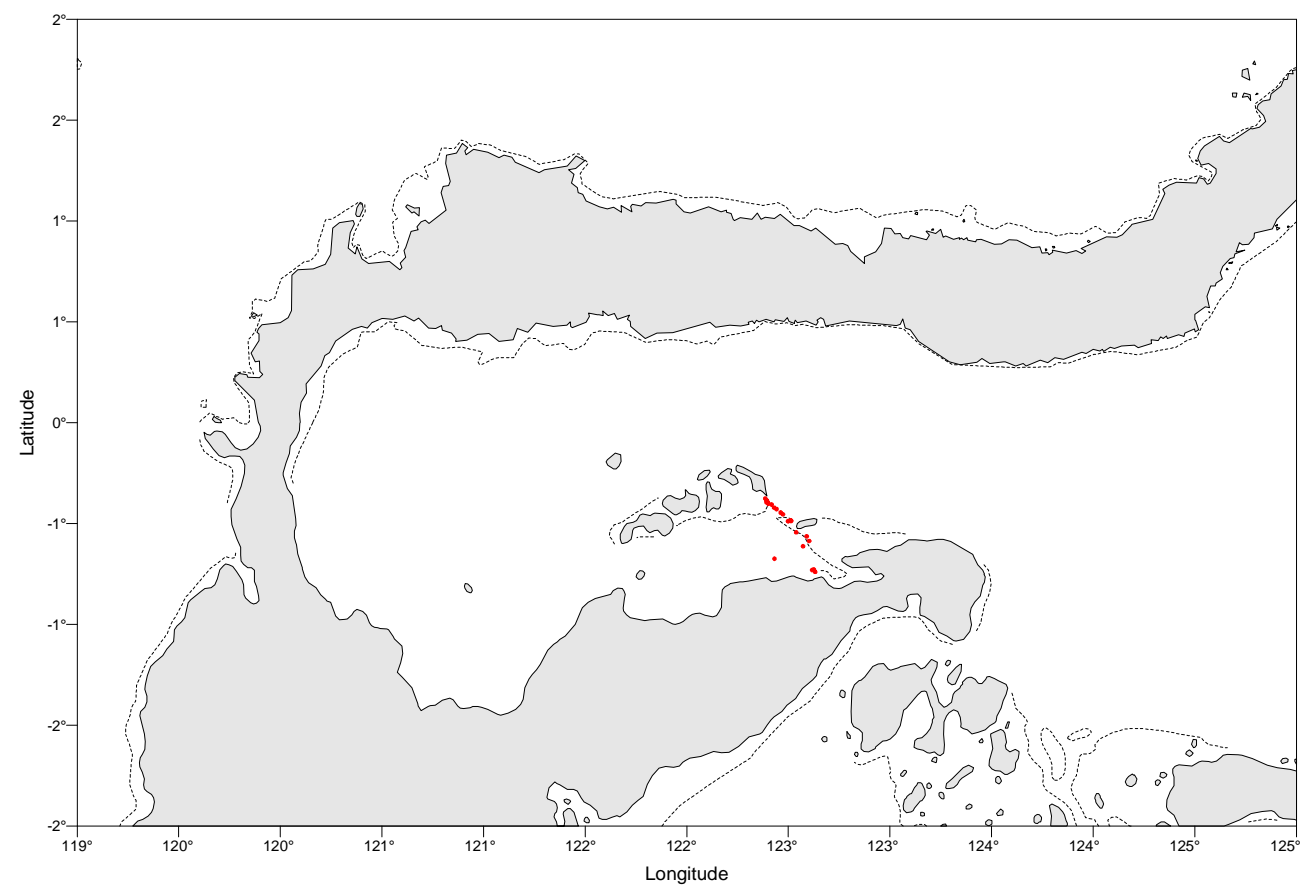

Gambar 3. Posisi fishing ground nelayan pancing pada musim timur.

\section{Hasil Tangkapan}

Hasil tangkapan pancing dasar pada umumnya merupakan jenis-jenis ikan karang yang mempunyai nilai ekonomis yang cukup tinggi seperti sunu super (Plectropomus leopardus), sunu macan (Plectropomus areolatus), bone-bone (Plectropomus oligocanthus), goropa gomes atau moso (Ephinephelus fuscoguttatus), goropa tikus (Cromileptes altivelis), ekor bulan (Variola sp.), kakap (Lutjanus sp.), daging putih atau lencam (Lethrinidae), suntung batu (Sephia sp.) gurita (Octopus), bobara (Carangoides sp.), bobot (Pristipomoides sp.), guntur (Aprion sp.), dan lain-lain. Hasil tangkapan pancing dasar pada bulan Mei sampai dengan Desember 2004 disajikan pada Gambar 4.

Pada tahun 2004 hasil tangkapan bulan Juni berada pada titik terendah yaitu $4.678,7 \mathrm{~kg}$ sedangkan hasil tangkapan tertinggi pada bulan September yaitu $11.254,6 \mathrm{~kg}$. Hasil tangkapan cenderung meningkat pada musim timur sampai dengan awal musim peralihan (bulan Juni sampai dengan September) dan pada awal musim barat (bulan Desember). Hasil tangkapan pada musim peralihan cenderung mengalami penurunan, hal ini dapat disebabkan oleh pergeseran musim yang belum stabil sehingga menyulitkan nelayan dalam melakukan penangkapan.

\section{Komposisi Jenis Hasil Tangkapan}

Pada umumnya hasil tangkapan pancing dasar didominasi oleh jenis kerapu atau grouper (Serranidae), kakap (Lutjanidae), daging putih atau lencam (Lethrinidae), dan suntung batu (Sephia sp.) serta gurita (Octopus sp.). Jenis ikan daging putih atau lencam (Lethrinidae) pada umumnya mendominasi hasil tangkapan setiap bulan dengan persentase rata-rata tertangkap $35,04 \%$. Jenis-jenis kerapu atau Serranidae (Plectropomus sp., Ephinephelus sp., Variola sp.) dan jenis-jenis kakap atau Lutjanidae (Lutjanus sp., Aprion sp., dan 


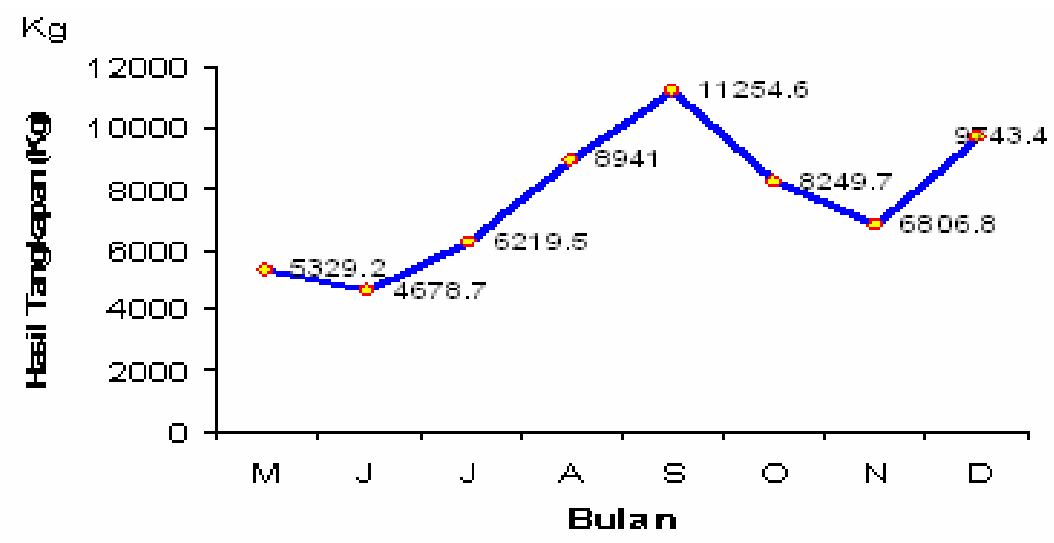

Gambar 4. Trend hasil tangkapan pancing dasar pada bulan Mei sampai dengan Desember 2004.

Pristipomoides sp.) yang merupakan sasaran tangkapan utama memiliki persentase rata-rata tertangkap cukup tinggi yaitu masing-masing 18,96 dan $18,82 \%$. Sedangkan jenis tangkapan lain yang juga mendominasi adalah gurita (Octopus sp.) yang rata-rata mencapai $13,45 \%$, suntung batu (Sepia sp.) rata-rata $3,34 \%$. Jenis-jenis ikan demersal karang yang dominan tertangkap alat tangkap pancing dasar di Kepulauan Togean disajikan pada Gambar 5. Komposisi hasil tangkapan bulan Mei sampai dengan Desember 2004 disajikan pada Gambar 6.

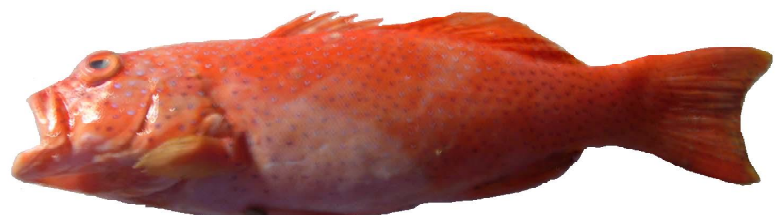

Plectropomus leopardus (sunu super)
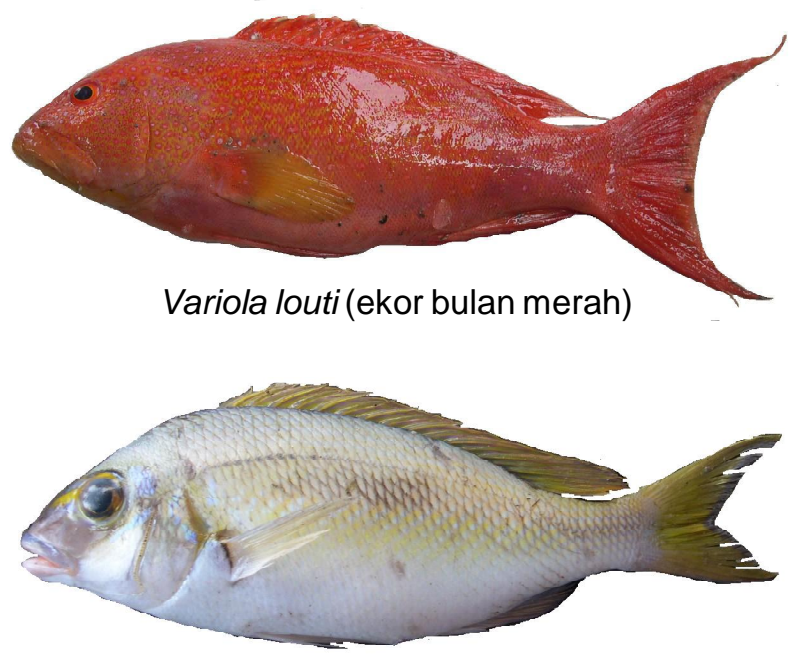

Lethrinus sp. (lencam atau daging putih)

\section{Laju Tangkap}

Data laju tangkap diperoleh melalui pengambilan contoh di salah satu pengumpul ikan (padola) di PPI Pagimana, Kabupaten Banggai serta pengambilan contoh langsung dari beberapa nelayan. Laju tangkap perikanan demersal pada bulan Mei sampai dengan Desember 2004 di Kecamatan Pagimana disajikan pada Gambar 7.

Dari data tersebut diperoleh informasi bahwa pada bulan Mei sampai dengan Desember 2004 laju

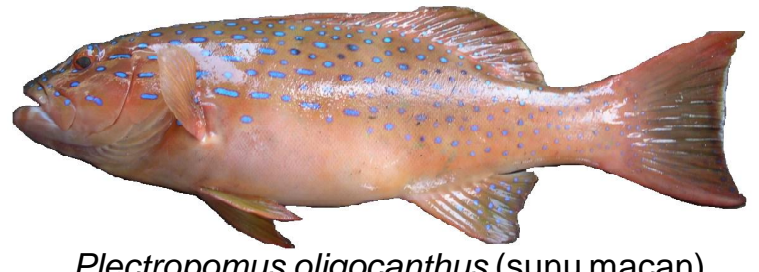

Plectropomus oligocanthus (sunu macan)

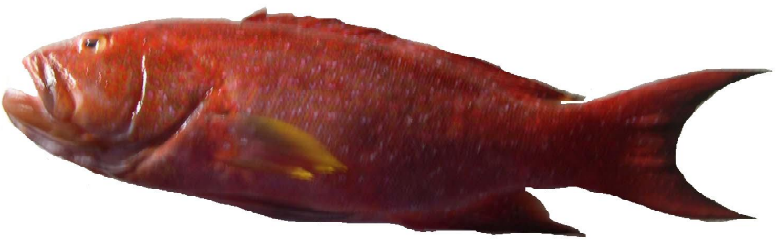

Variola albimarginata (ekor bulan hitam)

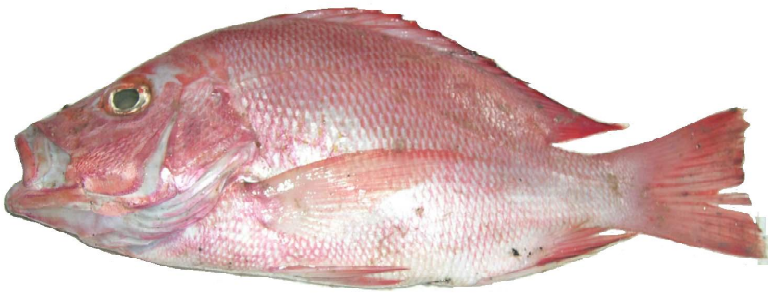

Lutjanus malabaricus (bambangan)

Gambar 5. Beberapa jenis ikan karang yang tertangkap pancing ulur di Kepulauan Togean. 

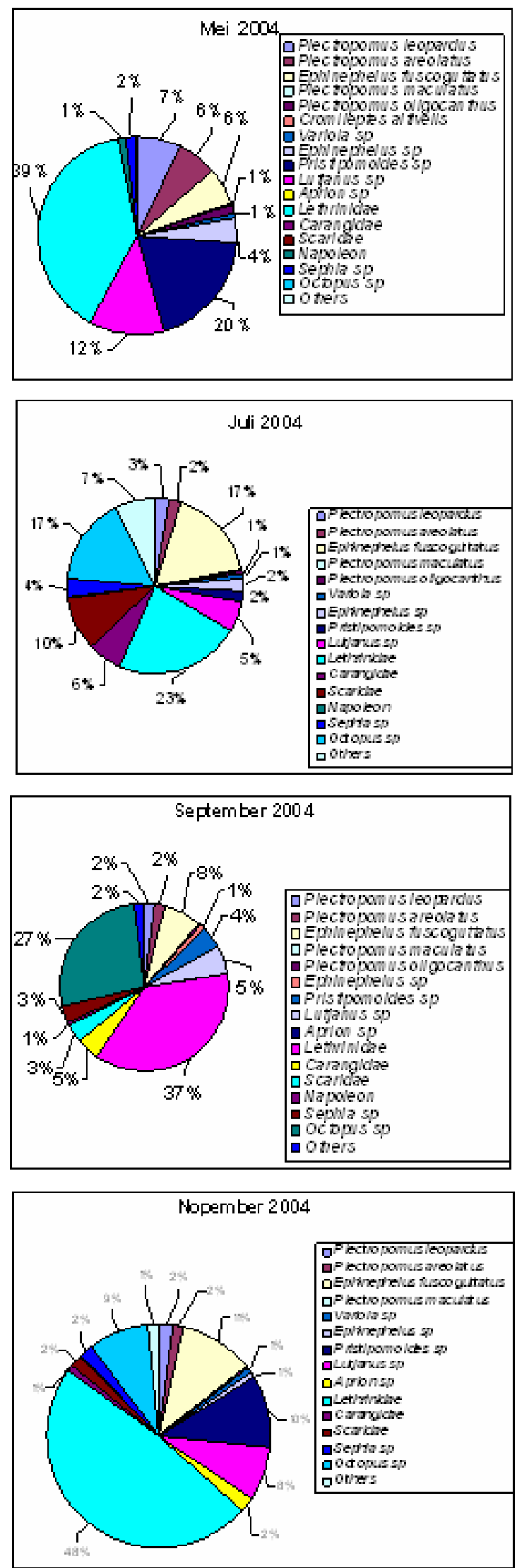
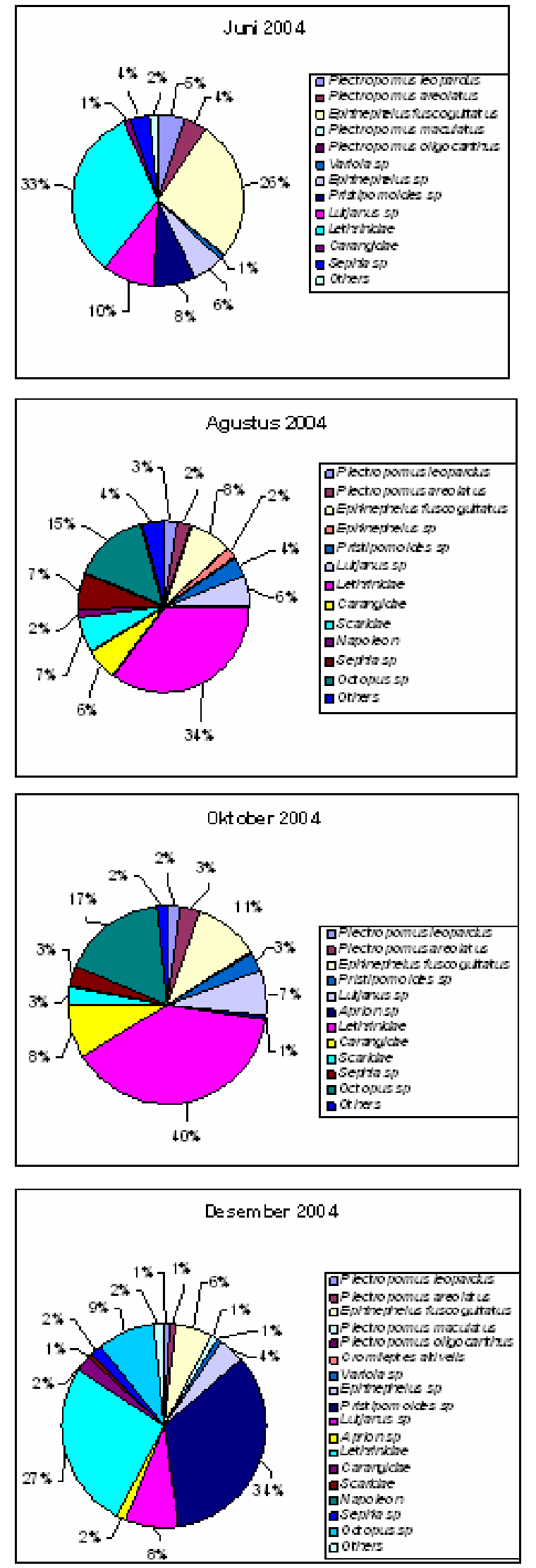

Gambar 6. Komposisi jenis hasil tangkapan per bulan pada tahun 2004 (bulan Mei sampai dengan Desember). 


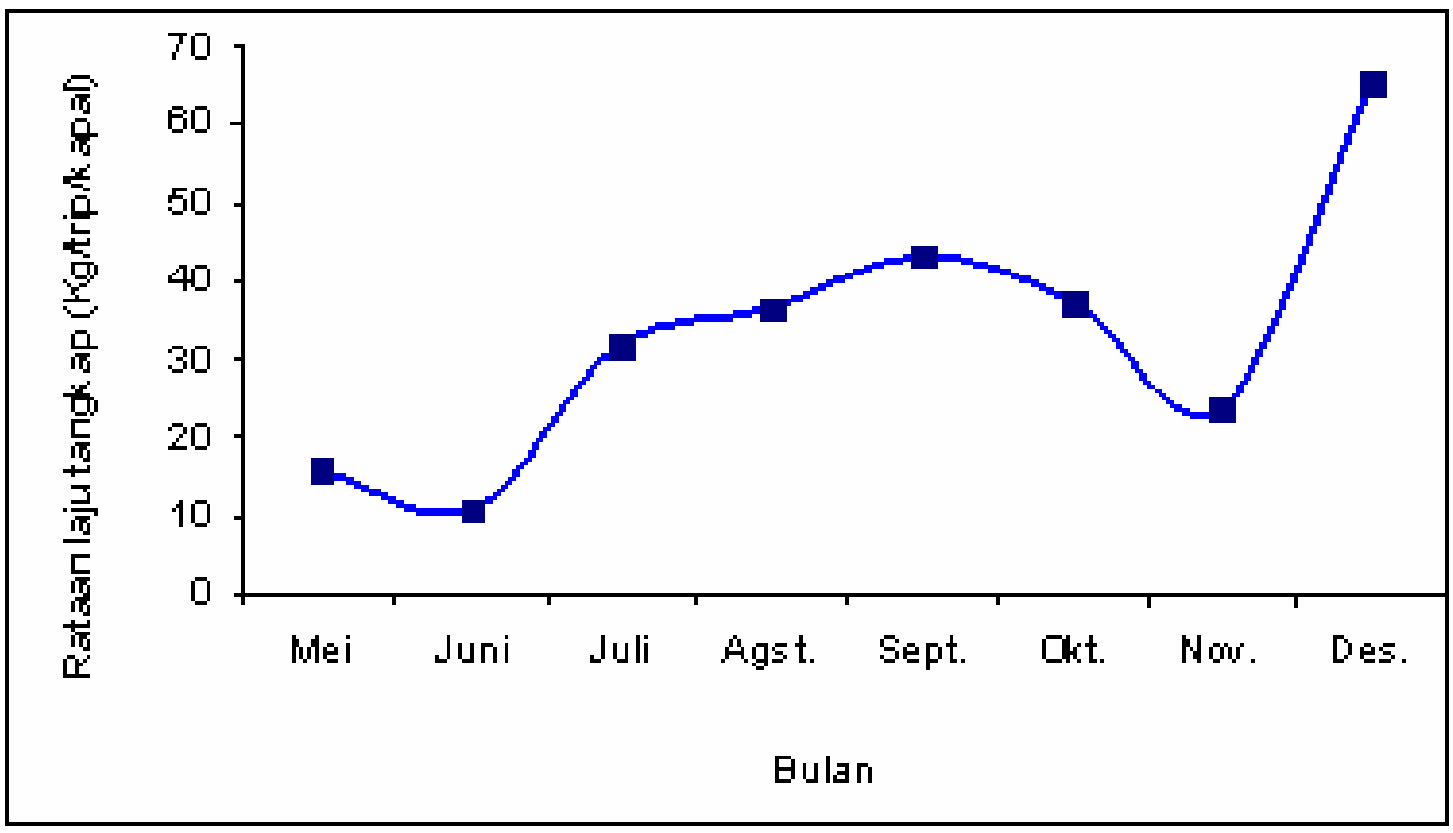

Gambar 7. Laju tangkap (kg per kapal per trip) bulan Mei sampai dengan Desember 2004.

tangkap harian berkisar antara 10,8 sampai dengan $65,4 \mathrm{~kg}$ per kapal per hari. Laju tangkap harian terendah pada bulan Juni dan tertinggi di bulan Desember 2004. Kecenderungan meningkat laju tangkap harian di bulan Desember diduga karena persaingan harga ikan di pasaran yang semakin meningkat. Sebagai contoh bahwa harga ikan di tingkat nelayan kepada pengumpul pada bulan Oktober 2004 untuk jenis ikan sunu super (Plectropomus leopardus) Rp.33.000,- menjadi Rp.45.000,- pada bulan Desember 2004, kakap yang semula Rp.12.000,- menjadi Rp.18.000,-, dan seterusnya. Kenaikan harga ini terjadi bahkan dapat mencapai $60 \%$ untuk jenis ikan lain. Selain itu, meningkat laju tangkap ini juga dapat disebabkan oleh semakin meluas daerah penangkapan (fishing ground), pada musim timur pada umumnya nelayan hanya menangkap di sekitar Kepulauan Togean, tetapi pada musim barat lahan penangkapan meluas ke arah perairan Pulau Buaya-Bualemo.

\section{Aspek Biologi}

Pengukuran panjang dan bobot ikan dominan dilakukan 2 tahapan, yaitu pengukuran yang dilakukan pada bulan Agustus 2004 yang mewakili musim timur dan bulan Desember 2004 yang mewakili musim barat. Secara umum, jenis ikan dominan pada ke-2 musim ini berbeda.

Dari hasil pengamatan di PPI Pagimana pada bulan Agustus 2004 (musim timur), komposisi hasil tangkapan nelayan pancing yang berhasil dikumpulkan dari beberapa padola (pengumpul ikan) terdapat 2 famili yang dominan, yaitu famili Serranidae (kerapu) dan famili Lutjanidae (kakap). Pada famili Serranidae terdapat 13 jenis kerapu (groupers) yang terdiri atas 6 spesies dari genus Ephinephelus, 2 spesies dari genus Cephalopholis, 3 spesies dari genus Plectropomus, dan 2 spesies dari genus Variola. Famili Lutjanidae terdiri atas 4 spesies dari genus Lutjanus, kemudian spesies Pinjalo pinjalo, Pristipomoides typus, dan Aprion virescens.

Hasil pengamatan pada bulan Desember 2004 (musim barat), komposisi hasil tangkapan yang dominan yaitu spesies Ephinephelus areolatus, E,fuscoguttatus, Plectropomus areolatus (Serranidae), dan Lutjanus malabaricus (Lutjanidae).

Pada musim timur pengukuran dilakukan pada jenis ikan dominan yang terdiri atas ikan-ikan kerapu (Serranidae) seperti Variola albimarginata dan Plectropomus leopardus, sedangkan jenis kekakapan (Lutjanidae) pada saat pengamatan tidak menunjukkan jumlah yang signifikan. Hasil pengukuran terhadap hasil tangkapan dominan pada musim timur disajikan pada Gambar 8. Ukuran panjang jenis ikan ekor bulan (Variola albimarginata) yang tertangkap berkisar antara 24 sampai dengan $34 \mathrm{~cm}$, yang didominasi oleh ikan yang berukuran $24 \mathrm{~cm}$. Jenis ikan sunu super (Plectropomus leopardus) yang tertangkap mempunyai ukuran panjang yang berkisar antara 28 sampai dengan $49 \mathrm{~cm}$. Hasil pengukuran terhadap hasil tangkapan dominan yang didaratkan di PPI Pagimana pada pengamatan bulan Desember 2004 disajikan pada Gambar 9. 

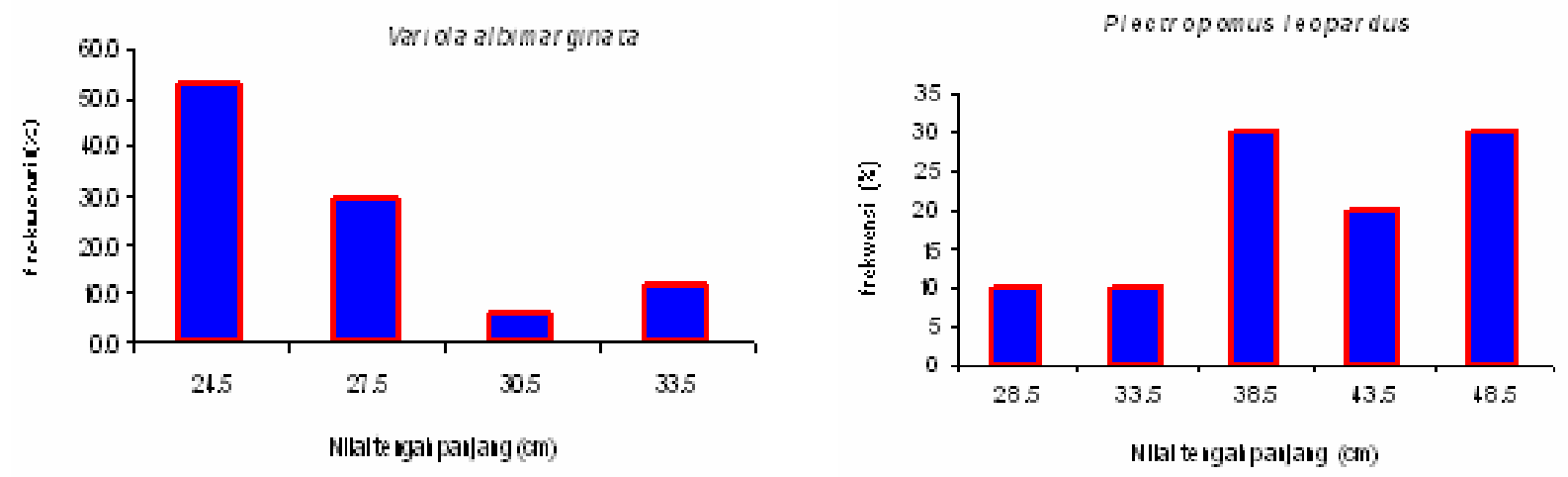

Gambar 8. Sebaran ukuran panjang beberapa jenis ikan dominan yang tertangkap pancing dasar pada bulan Agustus 2004.

Pada umumnya ikan kerapu coklat (Ephinephelus areolatus) yang tertangkap mempunyai ukuran 40 sampai dengan $82 \mathrm{~cm}$ dan didominasi oleh ikan-ikan yang mempunyai nilai tengah panjang $47 \mathrm{~cm}$. Ikan kakap merah (Lutjanus malabaricus) mempunyai ukuran panjang yang berkisar antara 40,5 sampai dengan $72,5 \mathrm{~cm}$ yang didominasi oleh ikan yang mempunyai panjang sekitar $72 \mathrm{~cm}$. Jenis ikan sunu macan (Plectropomus areolatus) yang tertangkap dengan panjang berkisar antara 39 sampai dengan $64 \mathrm{~cm}$ dan didominasi oleh ikan berukuran sekitar 44 $\mathrm{cm}$. Kerapu muso atau gomes (Ephinephelus fuscoguttatus) yang tertangkap pada umumnya memiliki ukuran yang lebih besar bila dibandingkan dengan jenis ikan lain, yaitu mempunyai kisaran panjang antara 64 sampai dengan $89 \mathrm{~cm}$ dan didominasi oleh ikan berukuran sekitar $64 \mathrm{~cm}$.

Ukuran jenis-jenis ikan yang tertangkap ini pada umumnya merupakan ukuran ekspor. Dengan ada perusahaan pengekspor ikan-ikan demersal karang baik dalam bentuk frozen, segar maupun fillet, nelayan di Kepulauan Togean tidak kesulitan dalam memasarkan hasil tangkapan. Sehingga pengusahaan penangkapan ikan demersal karang di
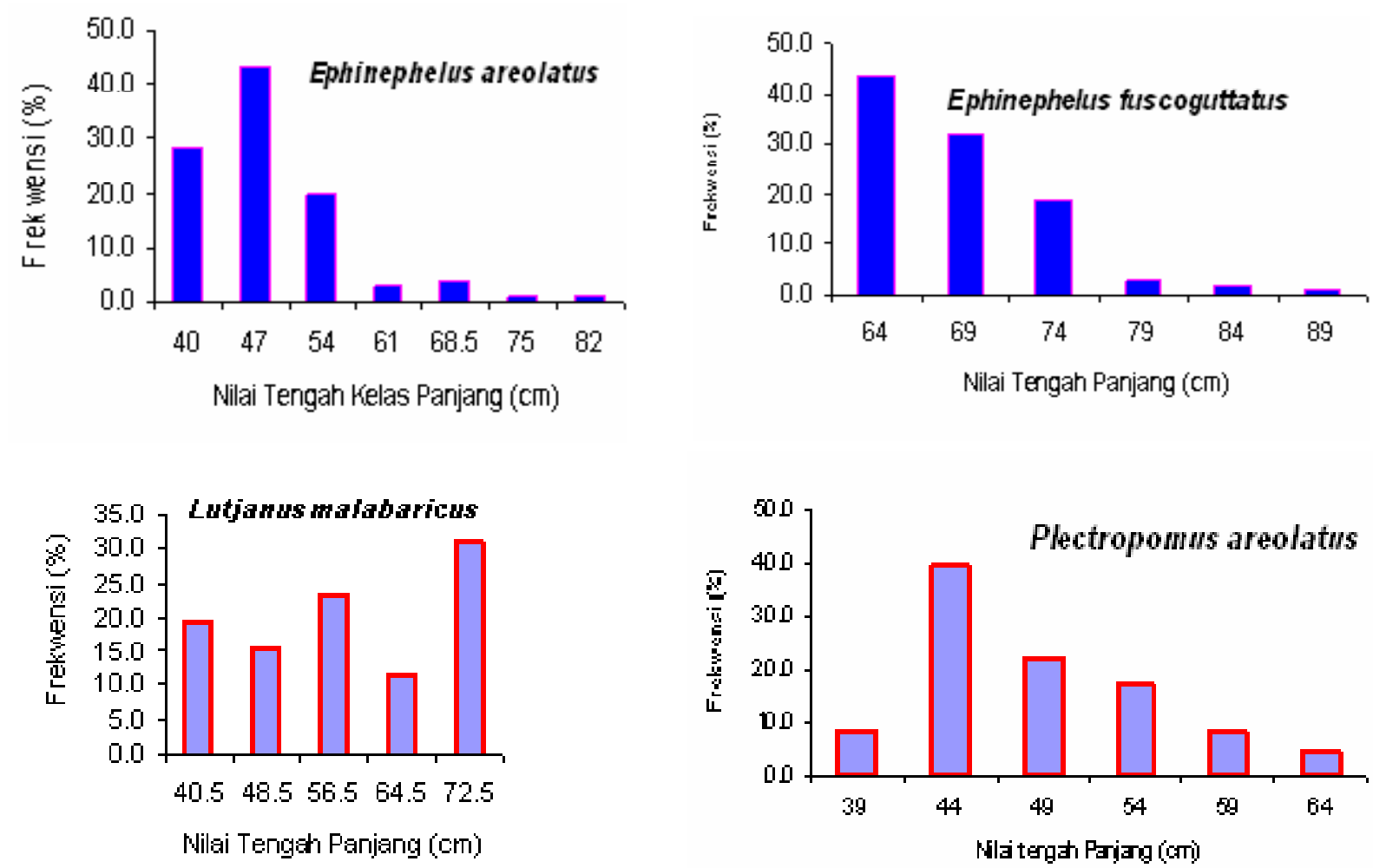

Gambar 9. Sebaran ukuran panjang beberapa jenis ikan dominan yang tertangkap pancing dasar pada bulan Desember 2004. 
wilayah ini relatif akan terus mengalami perkembangan. Pemantauan aktivitas penangkapan nelayan di wilayah ini harus dilakukan untuk menghindari terjadi penangkapan yang illegal maupun penangkapan yang tidak memperhatikan kelestarian.

\section{KESIMPULAN}

1. Alat tangkap yag digunakan dalam aktivitas penangkapan ikan demersal karang di perairan Kepulauan Togean adalah pancing dasar.

2. Daerah penangkapan pada musim barat adalah perairan Pulau Buaya-Bualemo, selain itu daerah penangkapan juga ke sekitar Pulau Poat, Pulau Bangoh, sampai dengan Tanjung Keramat.

3. Pada musim timur, nelayan pada umumnya menangkap di sekitar Kepulauan Togean, terutama di perairan Pulau Poat dan perairan Tanjung Keramat di Pulau Waleabahi yang merupakan daerah wisata dan konservasi terumbu karang.

4. Penangkapan ikan ke sekitar Kepulauan Togean (Pulau Poat, Pulau Bangoh, dan Tanjung Keramat) dilakukan sepanjang tahun, hal ini karena daerah penangkapan tersebut relatif dekat dan mudah dicapai.

5. Jenis hasil tangkapan dominan adalah ikan kerapu (Serranidae) dan jenis-jenis kakap (Lutjanidae).

6. Laju tangkap sepanjang tahun 2004 berkisar antara 10,8 sampai dengan $65,4 \mathrm{~kg}$ per kapal per hari.

7. Ikan yang tertangkap pada umumnya berukuran besar dan layak ekspor.
Persantunan:

Hasil dari kegiatan riset pengkajian stok perikanan Teluk Tomini T.A. 2003-2004 di Balai Riset Perikanan Laut

\section{DAFTAR PUSTAKA}

Anonim. 2001. Pengkajian stok ikan di perairan Indonesia. Pusat Riset Perikanan Tangkap. Departemen Kelautan dan Perikanan. Bekerjasama dengan Pusat Penelitian Oseanologi. Lembaga Ilmu Pengetahuan Indonesia. Jakarta.

Badrudin, M., B. Gafa, \& N. Naamin. 1992. Potensi sumber daya ikan di perairan Laut Maluku dan Teluk Tomini. Jurnal Penelitian Perikanan Laut. No.65. Balai Penelitian Perikanan Laut. Jakarta. Hal.19-29.

Gafa, B. \& W. Subani. 1993. Studi pengaruh rumpon terhadap perilaku ruaya ikan cakalang, Katsuwonus pelamis, dan madidihang, Thunnus albacares dengan metode tagging kawasan Indonesia Timur. Jurnal Penelitian Perikanan Laut. No.73. Balai Penelitian Perikanan Laut. Jakarta. Hal.65-78.

Gloefert-Tarp, T. \& P. J. Kailola. 1985. Trawled fishes of southern Indonesia and Northwestern Australia. Australia development assistance Bereau. Directorate General of Fisheries of Indonesian and German Agency for Technical Cooperation. National Library of Australia.

Heemstra, P. C \& J. E. Randall. 1993. Groupers of the world. FAO Species Catalogue. 